\title{
Research on the Practical Teaching System Reform of Computer Hardware Courses
}

\author{
Yi Qian* \\ Department of Information Science and Technology, Taishan University, Taian 271000, Shandong Province, China \\ *Corresponding author: Yi Qian, bjkdqy@126.com

\begin{abstract}
This study analyzes the current situation of the practical teaching system of computer hardware courses in local undergraduate colleges, scrutinizes the experimental environment construction, contents, and methods of computer hardware courses, and proposes a new practical teaching system for computer hardware courses, so as to meet the needs of transformation and development as well as application-oriented talent training.
\end{abstract}

Keywords: Core courses; Computer hardware courses; Practical teaching system

Publication date: December 2021; Online publication: December 23, 2021

\section{Introduction}

All local undergraduate colleges and universities are actively fine-tuning the talent training strategy in order to realize the transformation and development of local undergraduate colleges and universities into applied technology colleges and universities ${ }^{[1,2]}$. This does not only comply with the transformation trend of economic development, but also meet the internal needs of local undergraduate colleges and universities. In the process of talent training in local undergraduate colleges and universities, practical teaching is an important link to cultivate students' professional core competence. Strengthening practical teaching is an important way to improve students' comprehensive quality and cultivate high-quality talents for the society ${ }^{[3-5]}$. Its advantage is that it can combine theoretical knowledge with practice and improve students' understanding as well as their skills in applying theoretical knowledge. Therefore, in the transformation process of local undergraduate colleges and universities, the reform of the practical teaching system is the key to transformation ${ }^{[6-8]}$.

Computer hardware courses are core courses of the computer specialty. Strong practicality is one of its outstanding characteristics. Reforming the practical teaching system of computer hardware courses and improving the quality of practical teaching can improve students' practical skills, establish engineering consciousness, cultivate innovation skills, and enhance employment competitiveness.

\section{Current situation of the practical teaching system of computer hardware courses in China}

After years of development, China's computer engineering education has met the needs of its economic construction. However, there is still a huge gap in the industrial demand for practical skills. The curriculum of computer hardware courses varies from university to university, but it generally includes circuit and electronics, digital logic, computer composition principle, assembly language, single chip microcomputer, embedded system, architecture, etc. The first five courses are relatively basic low-level courses; single chip microcomputer and embedded system are highly applicable courses, while architecture is a theoretical course. 
For excellent local research universities, such as those under Project 985 and Project 211, the setting of these courses' curriculum system has been reformed in recent years, and initial results have been achieved. However, these practical teaching reforms have been put forward according to the characteristics of "research-oriented" colleges and universities. Due to the great disparity in technical strength and capital, the reform of the practical teaching system is not suitable for local undergraduate colleges and universities. For most local undergraduate colleges and universities that need to be transformed, it is difficult for this imitative practical teaching system to adapt to the characteristics of local undergraduate colleges and universities' own talent training due to several problems.

(1) The experimental equipment is old and completely detached from the development of new technology.

Many experiments in low-level hardware courses are still using the solidified experimental box of more than ten years of age, which completely lags behind the current development level of hardware technology.

(2) The experimental methods and means are backward.

The traditional experimental box has many disadvantages. Most experiments are confirmatory, and students do not need to understand the principle of these experiments. These confirmatory experiments can be completed just by connecting wires, turning the analog switch, and observing the light in line with the requirements of the experimental instruction. As a result, students' design ability and innovation skills are not brought into play, and the traditional experimental means are restricted by time and space.

(3) The experimental content cannot keep up with the development of application technology.

The design of experimental project is inseparable from experimental equipment. Old experimental equipment cannot be used to complete novel experimental projects which are closely related to application.

(4) The experimental class hours are insufficient.

In the setting of traditional hardware courses, experimental classes are only an adjunct to theoretical classes. The class hour ratio of theoretical classes to experimental classes is usually 3:1. Experimental classes cannot meet the training needs of hardware application technology talents. In addition, the curriculum design is not valued. Only a few hardware professional courses have carried out curriculum design; however, the effect of the curriculum design is not ideal. The topic selection of the curriculum design is also not updated in time and is not in line with the needs of social application. Students have no practice conditions and interest for independent practice during their spare time. There is no space for extracurricular practical activities.

In short, in the process of transformation and development, the experimental funds and technical force in local undergraduate colleges and universities are weak, and the practical teaching system is flawed. This seriously hinders the cultivation of applied technical talents; therefore, the reform of the practical teaching system is imminent.

\section{A new practical teaching system for computer hardware courses}

Different forms and levels of disciplines should emphasize different skills. Otherwise, there would be homogenizations, which would violate the training goal of the Ministry of Education. As a result, the needs of employers for different types of computer professionals would not be met. In consideration of the professional skill requirements set by employers for computer graduates, the feedback about graduates upon participation in the enterprise workforce, and the experience in teaching practice in recent years, it is 
imperative to strengthen the cultivation of systemic skills among application-oriented talents.

Beginning from the goal of cultivating high-quality applied talents in Taishan University, after years of teaching practice, the university is positioned in such a way that it focuses on the cultivation of practical application skills. The focus is on strengthening practical teaching in several main aspects, such as digital circuit and functional component design, so as to improve students' design ability as well as highlighting the professional characteristics of application-oriented talents, which is closer to the needs of information technology enterprises for system design talents.

After several years of teaching practice, the university has adjusted and standardized the skills needed in system design. Special emphasis is placed on the training and cultivation of hardware system design skills, in order to meet the needs of social and economic development for professionals in information construction as well as to portray the professional characteristics of the university.

The practical teaching system reform is an all-round reform. The practical teaching system reform of computer hardware courses is aimed at the reform of a series of courses. Therefore, it involves a wide range of contents, and the reform measures are comprehensive. The process of reform is complex and cumbersome. An overall plan has been proposed for the training of talents majoring in computer science and technology. The design demonstration has been carried out from the aspects of training plan, curriculum, design of centralized practical teaching links, and the determination of practical teaching contents; in addition, corresponding measures have been taken.

\subsection{Objectives and class hour adjustments}

By analyzing the characteristics of each hardware course and its combination with the latest application technology, determine the practical teaching objectives of each course. According to the practical teaching objectives, the experimental class hours, curriculum design class hours, and extracurricular independent learning class hours are set.

According to the relevant reports of the Ministry of Education and the spirit of the conference, various investigations have been carried out, such as the investigation of recent graduates, the discussion and exchange with IT enterprises, and so on. Combined with the orientation of talent training, much effort has been made to refine the core competence of the major. The original professional training plan has been adjusted, and the experimental teaching has been fortified. The proportion of centralized practical teaching in the whole teaching plan has increased. The experiment and course design of hardware courses have been strengthened, and the corresponding credits have increased. It enriches the practical topics and their contents as well as increases the proportion of innovative design topics.

Specifically, a series of hardware courses based on digital logic, computer composition principle, assembly language, interface technology, and computer system structure have been formed in the curriculum. The ability of hardware analysis as well as software and hardware co-design have been strengthened. At the same time, on the basis of experimental exercises supporting relevant hardware courses, centralized practical teaching links such as curriculum design of the above courses have been added, with hardware system analysis and design as the main content. In the new talent training plan, the proportion of credits in centralized practical teaching has increased to more than $30 \%$ of the total credits.

\subsection{Reform of practical teaching platform}

In consideration of the actual application needs, the experimental project of hardware professional courses has been designed. The internal relationship between courses and the practical value of experimental projects are emphasized on, and certain traditional confirmatory experimental projects have been changed into design experiments. 
The traditional experimental equipment for computer science requires large investment in the early stage and has high maintenance cost in the later stage. The process of carrying out the experiment is limited by time, place, human, materials, and financial resources. The experimental teaching mode of combining traditional experimental equipment, virtual experimental environment, and various simulation software has been adopted. The research and development of virtual instrument experimental platform is the nucleus of vigorous research and production in technology-developed countries. It provides the essential development tools for various applications, such as data acquisition, instrument control, measurement and analysis, data display, and so on.

The excellent virtual experiment software at home and abroad is used to carry out the application and research on virtual experiment teaching. With the operation training of physical experimental equipment, such as the advanced experimental box, students' practical skills, independent design ability, and innovation skills can be effectively trained. Therefore, various experimental teaching methods have been adopted along with the orientation of applied talent training and laboratory construction in Taishan University.

\subsection{Reform of practical teaching content}

While adjusting the experimental equipment, the practical teaching content has also been reformed. From the original wiring and verification experiment, it has gradually improved to the logic design of small digital circuit. Design and innovative experiments such as memory, arithmetic unit, and controller design, test and CPU design, as well as debugging have been added. The purpose is to further improve students' system design ability and innovation skills as well as to meet the quality requirements of social information construction for professionals.

Electronic design automation (EDA) has been introduced into the experiments of basic hardware courses. Virtual hardware experiment is realized by simulation software, which is in line with international advanced electronic design technology. Hardware materials with strong practical development have been purchased. The popular 51 series development board is used in the single chip microcomputer course, and the well-known arm system-on-chip is used in the embedded system course. In this way, students can really develop valuable systems and products with these experimental materials.

The new curriculum design for hardware professional courses should be combined with practical application, and real cases should be introduced into the curriculum design. Emphasis should be on the cultivation of students' application and innovation skills in the link of curriculum design as well as their independent hardware design ability and development skills.

Innovative practical projects should be carried out outside course hours. Laboratories should be opened during students' spare time, while learning resources should be available for students to study and practice independently. Students should be encouraged to participate in various competitions related to electronic design, single chip microcomputer design, and embedded system design, such as "Challenge Cup" competition. Students' design ability and development skills should be cultivated, so that their creative designs can directly become effective products.

Through the experimental teaching reform of main computer hardware courses, the understanding of computer system structure and the cultivation of system design ability have improved. It did not only effectively improve students' hardware design ability and development skills, but also accumulate experience for the construction and reform of other related courses.

\subsection{Reform of practical teaching assessment}

The practical teaching assessment should be strengthened. The traditional teaching assessment system mainly adopts the method of paper examination, focusing on the examination results. In order to cultivate 
high-quality application-oriented talents, the current assessment system must be reformed. The practical teaching assessment should be strengthened, and the proportion of assessment results should be increased. Students should be encouraged to practice independently, while innovative and design works should be emphasized and encouraged in practical assessments.

\section{Conclusion}

The computer specialty should keep pace with the times. By meeting the requirements of the current social and economic construction and development, only then it is possible to cultivate senior professionals in the IT industry who meet the needs of the society. Taking the practical teaching system reform of computer hardware courses as an example, this study explores the practical teaching system with its own characteristics and those of which are suitable for its development in local undergraduate colleges and universities. A scientific and reasonable practical teaching system, including the setting of experimental courses, the determination of experimental hours, the design of experimental projects, the selection of experimental methods, the realization of curriculum design, and so on has been established in view of the need of senior applied technical talents with certain theoretical basis, strong practical skills, and practical application skills. In the process of implementation, good teaching results have been achieved.

\section{Disclosure statement}

The author declares that there is no conflict of interest.

\section{References}

[1] State Council, 2010, Outline of National Medium- and Long-Term Education Reform and Development Plan (2010-2020).

[2] Gu B, Peng W, Ouyang X, 2012, Reflections on the Reform of Practical Teaching of Hardware Course for Computer Specialty. Computer Education, 2012(12): 19-21.

[3] Liu J, Li Z, 2010, Reform and Practice of Practical Teaching of Computer Hardware Courses. Experimental Technology and Management, 27(4): 130-132.

[4] Li Z, Fan W, 2013, Computer Hardware Practice Teaching System Under the Background of "Excellence Program". Computer Education, 2013(15): 42-47.

[5] Steering Committee of Computer Science and Technology Teaching in Colleges and Universities of the Ministry of Education, 2008, Practical Teaching System and Norms of Computer Science and Technology Specialty in Colleges and Universities, Tsinghua University Press, Beijing, 10.

[6] Steering Committee of Computer Science and Technology Teaching in Colleges and Universities of the Ministry of Education, 2008, Public Core Knowledge System and Curriculum of Computer Science and Technology Specialty in Colleges and Universities, Tsinghua University Press, Beijing, 10.

[7] Li S, Jin C, 2010, Research Report on Computer Hardware Series Courses and Experiments in the United States. Computer Education, 2010(15): 16-20.

[8] Liu L, Yan D, 2010, Design of Practical Teaching System Based on the Cultivation of Application Ability and Innovative Consciousness. Computer Education, 2010(10): 147-149. 